NASA Technical Memorandum 83637

\title{
Preliminary Investigation of a Two-Zone Swirl Flow Combustor
}

James A. Biaglow, Susan M. Johnson, and John M. Smith

Lewis Research Center

Cleveland, Ohio

Prepared for the

Twentieth Joint Propulsion Conference cosponsored by the AIAA, SAE, and ASME

Cincinnati, Ohio, June 11-13, 1984 
PRELIMINARY INVESTIGATION OF A TWO-ZONE SWIRL FLOW COMBUSTOR

\author{
James A. Biaglow, Susan M. Johnson, and John M. Smith \\ National Aeronautics and Space Administration \\ Lewis Research Center \\ Cleveland, Ohio 44135
}

Abstract

An experimental investigation was conducted to determine the effect of full-annular swirlingflow on a two-zone combustor design. Swirl flow angles of 25,35 , and 45 degrees were invest $i$ gated in a combustor design envelope typical of those used in modern engines. The two-zone combustor had 24 pilot-zone fuel injectors and 24

I main-fuel injectors located in the centerbody N between the pilot and swirl passage. Combustor $\dot{\omega}$ performance was determined at idle, and two parametric $589 \mathrm{~K}$ inlet temperature conditions. Combustor performance was highest with the 45 degree swirl vane design; at the idle condition combustion efficiency was 99.5 percent. The 45 degree swir? vane also produced the lowest pattern factor of the three angles and showed a combustor lean blowout limit below a 0.001 fuelair ratio. Combustor total pressure drop varied from a low of 4.6 percent for the 25 degree swirl to a high of 4.9 percent for the 45 degree swirl.

\section{Introduction}

The purpose of this investigation was to explore the concept of a full-annular swirl-flow combustor in a practical design envelope with the goal of determining the merits and potential of such a combustor system. It was not the goal of this investigation to fully develop such a concept into an operational mode, but rather to only explore alternate approaches to this unique concept with the idea of advancing its application for use in future designs.

Previous swirl flow combustors have shown the potential to utilize high imposed body forces, increases in flame speed and high mixing rates to produce very uniform exit temperature profiles, lean burning, high efficiency, and low pollutant levels. These results were achieved in augmentors, can combustors, straight-through annular and variable geometry systems that were not typical of current and advance aircraft engines. 1-4 In this present investigation the potential of swirling flow was explored in a two-zone, full-annular combustor design envelope, typical of that required for a current or advanced high pressure ratio engine. The combustor was designed to operate at idle conditions with the pilot only and with the pilot and main lit at all other conditions.

In addition to a more practical or conventional design envelope, particular emphas is was also placed on determining the effect of swirl flow angle with a limited number of main power fuel flow injectors on combustor performance. It was not surprising that previous investigations of full annular swirl combustors had uniform exit profiles. They had large numbers of fuel injectors or used large pre-mixed fuel-air annular passages. Such uniform-fuel distribution systems would naturaliy contribute significantly toward uniform exit temperature distribution and good combustor performance. The question addressed further by this study was how a swirl combustor would behave with a limited number (24) of standard nozzles for main power fuel injection. Such a system, typical of current aircraft design would provide a less complicated and costly one to maintain than systems that require more than two to three times the number of fuel injectors investigated in this program. 5

For the preliminary phase of this investigation only the swirl vane angle was changed, there were no air flow splits, liner contour or fuel nozzle changes. Test conditions included: idle; $492 \mathrm{~K}$ inlet-air temperature, $0.32 \mathrm{MPa}$ inlettotal pressure, parametric; $589 \mathrm{~K}$ inlet air temperature, $0.52 \mathrm{MPa}$ inlet-total pressure and a second parametric condition of $589 \mathrm{~K}$ inlet-air temperature and $0.83 \mathrm{MPa}$ inlet-total pressure. All tests, were conducted using ASTM-A1 fuel.

Apparatus and Procedure

A schematic of the test facility is shown in Fig. 1. A natural gas preheater was used to heat the combustor inlet-air to the desired maximum temperature of $589 \mathrm{~K}$. Air was supplied by the center's air system with a maximum test flow rate of $20 \mathrm{~kg} / \mathrm{sec}$ and a range of total pressure from 0.32 to $0.83 \mathrm{MPa}$. Quench water to cool the combustor exhaust system was provided by a cooling tower supply. A more detailed description of the test facility is given in Ref. 6 .

\section{Combustor}

A cross section view of the two-zone combustor is shown in Fig. 2. Thirty-six swirl vanes of either 25,35 , or 45 degrees were located on the combustor inner diameter below the pilotzone. Figure 3 shows details of the swirl vanes and the typical ring to which they were attached for ease of interchangeability. To ignite the combustor a four-joule surface discharge ignitor located at 10 degrees from top dead center of the combustor was used. Twenty-four fuel nozzles and swirlers were located in the pilot-zone for startup and idle operation with an additional twentyfour main power fuel nozzles located on the centerbody just above the swirl channel. The combustor was designed such that; 56.7 percent of the airflow passed through the main swirl passage, 8.3 percent was used for inner liner cooling, 12.5 percent for outer liner cooling, 20 percent for pilot swirler flow and 2.5 percent for dome cooling. Figure 4 shows a photograph of the combustor with the inner liner removed.

\section{Instrumentation}

Combustor exit instrumentation consisted of three rotating probes each for temperature, gas 
sampling and pressure for a total of nine probes spaced 40 degrees apart. The set of three thermocouple probes, for example, were spaced 120degrees apart from each other. The probes were stepped every three degrees and swept 120-degree arcs for exit temperature data collection. Figure 5 shows the location of the nine exit instrument probe arms. Also shown in this figure is the location of four outer diameter wall taps used to monitor exit static pressure. Four additional static wall taps were located on the drum inner wall.

Data from the three exit temperature probes were connected to an online computer, programmed to drive a color CRT, which displayed a nine color graphic representation of the combustor exit temperature distribution. The colors were in terms that showed a local exit temperature variance defined as:

$\begin{aligned} & \text { Local temperature } \\ & \text { variance }\end{aligned}=\frac{T_{\text {exit, local }}-T_{\text {exit, average }}}{T_{\text {exit, avg }}-T_{\text {inlet, avg }}}$

Thus values from -0.8 (cold) to +1.0 (hot) in 0.2 increments showed the combustor distribution of any cold or hot spots for a particular test condition.

The gas sampling probe had five ports connected to a common manifold that was connected to the control room gas analys is equipment. The probes were water cooled to freeze the chemical reaction at the exit plane and then steam heated to prevent condensation of unburned hydrocarbons.

A $3.2 \mathrm{~cm}$ thick flange was inserted between the combustor exit and the instrument drum so that a radial traversing yaw probe could be used to measure the exit swirl angle. The probe was located 15 degrees from the top dead center looking upstream and was moved by a computer controlled actuator to five positions at centers of equal area. A null pressure transducer was used to determine the angle of airflow at the exit plane using two static pressure readings on either side of a total pressure port. When the two static pressure readings were equal, the total pressure port would be facing directly into the airstream. The angular position of the yaw probe was then recorded by a controller that was linked to a computer for a digital read-out. This probe was water cooled so it would withstand the combustor exhaust temperature.

\section{Test Procedure}

The combustor operating conditions are shown in Table 1 and include an idle condition and two $589 \mathrm{~K}$ parametric test conditions. Ignition of the combustor was always accomplished by establishing flame in the pilot zone. Once the pilot was lit, the main fuel nozzles were actuated and the combustor brought to the desired exit operating conditions. If ignition did not occur within one minute, the surface discharge ignitor was turned off and the fuel lines purged with gaseous nitrogen for five minutes. Test data were recorded using a real time mini-computer. During the test an IBM 370 computer was used to reduce and process the extensive data batch readings.

\section{Results and Discussion}

Significant improvements were obtained in combustor performance by increasing the main swirler flow turning angle. The following section discusses these improvements in performance using the measured values of exit temperature distribution, exit angle, pilot to main fuel flow ratio and combustor exit parameters.

\section{Exit Temperature Distribution}

Figure 6 presents the computer graphic representation of the three types of combustor exit temperature distribution with the three swirl angles operating only on pilot fuel injection. The test conditions for the temperature distributions in Fig. 6 were: inlet Mach number of 0.32 , inlet-air temperature $589 \mathrm{~K}$ and inlet-total pressure of $0.52 \mathrm{MPa}$. The fuel-air ratio was 0.012 for the 25-degree turning vanes and 0.016 for the 35 and 45-degree turning vanes. The 25-degree turning vane tests were limited to 0.012 fuel-air ratio due to high pattern factors. The lighter checkered areas in these figures (mainly in the center and outer diameter) are the major hot spots and the lighter cross marked areas (mainly on the inner diameter) are the coldest areas. From these figures can be seen the gradual reduction of the number and severity of hot spots as the swirl angle increased from 25-degrees to 35-degrees to finally 45-degrees. For example, in Fig. 6(a) for the 25-degree swirl vane design almost 24 lighter areas corresponding to the 24 pilot swirlers can be seen. In Fig. 6(c) for the 45-degree swirl vane only 3 such areas are discernible.

Figure 7 presents the same condition as Fig. 6 except that both the pilot and main-fuel injectors were operating. In these figures, the fuel flow to the pilot and main was spit equally aird the sum of their flow is equal to that of the pilot fuel-injector-only operation. Ignition of the main fuel injector shows a general improvement in the severity and number of both hot and cold areas for all three swirl angles. The cooler inner diameter in Figs. 6 and 7 is due to the following reasons: The main nozzles are located in an expansion area between the pilot injector and the main injector. The main injectors are also required to make the fuel penetrate and mix in the high velocity swirl flow. The combustion in this expansion area and the centrifugal force of the swirling flow, causes the heavier unburned fuel to move toward the outer diameter. The net result is more burning in the outer diameter than is desired and a cold inner diameter.

Measurements of the quality of the exit temperature profile was determined by calculating the combustor exit pattern factor which is defined as:

Pattern Factor $(\delta)=\frac{T_{\text {exit }} \text { max }_{\text {exit }}-T_{\text {exg }}-T_{\text {in }}}{T_{\text {exg }}}$

The best pattern factor achieved for the three swirl vane designs investigated was for the 45-degree swirl. The pattern factor for the 45-degree swirl ranged from 0.38 for the combined 
pilot and main operation to a high of 0.6 for pilot only operation. Values of the 35-degree swirl vane ranged from 0.4 to 0.8 while those of the 25-degree swirl design approach as high as 1.0. The high pattern factors were found in part to be caused by three mismatched pilot-fuel nozzles that were found after testing to be flowing ten percent higher than the rest. Elimination of the three high flowing nozzles would have significantly reduced the exit pattern factors for all three swirl angle combustors.

\section{Exit Angle Measurement}

In order to assess the magnitude of the centrifugal force generated by the different swirl angle and to determine how much more mixing potential there was to utilize, measurements of combustor exit swirl angle were made and are plotted in Figs. 8 and 9 . At isothermal conditions, for the 45-degree swirler vanes, approximately 8degrees of swirl was lost-over the height of the annulus exit. The majority of this lost swirl was attributed to an increased axial component coming from the pilot and a corresponding decrease in the tangential component of the flow coming from the swirl channel and having to exit the combustor at a larger radius. Subsequently further large angles were lost due to the axial component being increased by the addition of heat. The loss in the 35-degree swirl was sufficient to el iminate any effect of swirl in the outer-half of the combustor. Instrument failure prevented measurement of the combustor exit angle for the 25-degree swirl vanes.

Calculation of the maximum centrifugal force applied to the flow exiting the swirl channel was made using:

$$
G_{\text {Force }}=\frac{v^{2}}{R_{g}}
$$

where $V=$ swirl channel tangential velocity, $R=$ the radius at the midpoint of the swirl vane exit and $g$ is the acceleration due to gravity. For an inlet temperature of $589 \mathrm{~K}$, inlet Mach number of 0.32 and the 45-degree swirl vane installed, the gravitational force was $1350 \mathrm{G}$ 's. Using the average of the measured exit isothermal angle from figure 9 the exit centrifugal force was $550 \mathrm{G}$ 's. These inlet and exit values seem quite large but if the $G$ field were calculated for a larger swirl angle than was tested, 60 degrees for example, the centrifugal force generated would easily be over $4000 \mathrm{G} ' s$. Corresponding similar increases to the exit $G$ force would occur as the inlet $G$ field is increased. Thus it is seen that for this combustor design there is still a potentially large area of $\mathrm{G}$ force effects to be investigated.

\section{Fuel Flow Ratio Effects}

Figure 10 shows the effect of fuel flow, (pilot to main) ratio on combustor exit angle and in part explains why improvements in pattern factor were difficult to achieve. The more fuel distributed to the center body ma in fuel injectors the more it was thrown to the pilot region causing the swirl to decrease in that region.
To reduce this problem future designs will have to employ one or more of the following; steeper inner diameter liner contours to force the air flow to follow the fuel replacement of the main fuel system for better main fuel-air mixing or increasing the number and angle of the turning vanes. Increases in turning angle are plotted against percent pilot flow in Fig. 11 and showed a very noticable improvement in combustion efficiency when going from 25-degrees to 35-degree swirl.

\section{Emissions}

Figure 12 presents the exit pollutant data for a range of fuel flow ratios of pilot to main from 4.0 to 0.25 . Of particular note in Fig. 12 is the large decrease in both unburned hydrocarbons and carbon monoxide in going from 35-degrees swirl to 45-degrees swirl. This decrease amounts to 75 to 90 percent reduction for unburned hydrocarbons and a equaliy impressive 50 to 60 percent reduction in the emission index of carbon monoxide. Oxides of nitrogen are included in this figure and also shows a reduction as the swirl angle is increased from 35-degrees to 45-degrees. However, the goal of some combustors is to obtain 1.0 grams of $\mathrm{NO}_{\mathrm{x}}$ per kilogram of fue ${ }^{5}$ which is quite a bit lower than the minimum value of 5.0 grams of $\mathrm{NO}_{x}$ per kilogram of fuel shown in Fig. 13. These large values of oxides of nitrogen may in part be attributed to the three mis-matched pilot fuel nozzles and the inability of the tested swirl angles to completely wash out the exit signatures from them.

\section{Combustor Performance}

The two zone conventional designed swirl flow combustor produced combustor performance levels typical of those required for a modern or future aircraft combustor design.?

Combustor exit pressure drop for the three swirl vane designs were: 4.6 percent for the 25 -degree swirl, 4.75 percent for the 35 -degree swirl and 4.90 percent of the 45-degree swirl. The ignition characteristic of the combustor was excellent, regardless of the swirl angle.

Ignition usually occurred during the first 15 seconds of a one minute start sequence. Idle combustion efficiency was a high of 99.5 percent for the 45-degree swirl and is reflected in the plots of unburned hydrocarbons and carbon monoxide in Fig. 14. High pressure parametric test results for the 45-degree swirl design are presented in Fig. 13. Lowest hydrocarbon and carbon monoxide levels were achieved for a 1.5 pilot to main fuel ratio. Oxide of nitrogen were lowest for a 0.66 pilot to main fuel ratio.

Measurements of combustor blow-out limits were conducted after each swirl angle idle test. With the idle operating at an 0.008 fuel air ratio the fuel flow was reduced enough to lower the fuel-air ratio in increments of 0.001 . After each reduction the temperature probes were cycled to look for areas in which the combustor had blown out. If there were none and the combustor maintained a temperature rise of $173 \mathrm{~K}$ it was considered still lit. Blow out occurred for the 
25-degree swirl design at a fuel-air ratio of 0.002 . The 35 degree swirl design blew out at a 0.001 fuel-air ratio and the 45 degree swirl design below 0.001 fuel-air ratio.

\section{Summary of Results}

Emissions and performance characteristics were determined for a two-zone, swirl-flow combustor using full-annular turning vanes of 25-degrees, 35-degrees and 45-degrees. The effects of combustor swirl flow angle were investigated at idle and two parametric $589 \mathrm{~K}$ inlet-air temperatures.

(1) The swirl-flow combustor concept showed the potential to utilize centrifugal forces to greatly enhance mixing, improve exit temperature pattern factor, increase efficiency and improve lean blow-out limits.

(2) The exit temperature gradients attributed to inferior mixing from a minimum number of fuel injectors can be substantially improved with swirling flow.

(3) The two-zone conventional design swirlflow combustor produced combustion efficiency greater than 99 percent along with low pressure loss and lean blow-out limits typical of a modern or future aircraft combustor design.

\section{References}

1. Roberts, P. B., White, D. J., and Shekleton, J. R., "Advanced Low Nox Combustors for Supersonic High-Altitude Aircraft Gas

Turbines," Solar Division of International Hanvester, San Diego, Calif., RDR-1814, Nov. 1975. (NASA CR-134889).

2. Clements, T. R., "Effect of Swirling Flow on Augmentor Performance-Turbojet Engines Application," Pratt a Whitney Aircraft, West Palm Beach, Fla., FR-6534, Nov. 1974. (NASA CR-134639)

3. Markowski, S. J., and Lohman, R. P., "Swirl Burner Combustion Zane Development Program, Final Report," AFA PL-TR-71-61, Aug. 1971.

4. Roberts, P. B., and Kubasco, A. J. "Investigation of a Low NOX Full-Scale Annular Combustor, "Solar Turbines Incorp., San Diego, CA., SR82-R-4621-36, Feb. 1982. (NASA CR-165518)

5. Roberts, P. B., Kubasco, A. J., and Sekas, N. J., "Development of a Low NO Lean Premixed Annular Combustor," ASME Paper 81-GT 40, Mar. 1981.

6. Adam, P. W., and Norris, J. W., "Advance Jet Engine Combustor Test Facility, "NASA TN D-6030, 1970.

7. "The Design and Development of Gas Turbine Combustors, Vol. 1., Northern Research and Engineering Corp., NREC Report No. 1344-1, 1980. 
TABLE I. - SWIRL FLOW COMBUSTOR TEST CONDITIONS

\begin{tabular}{|l|c|c|c|c|}
\hline $\begin{array}{c}\text { Test } \\
\text { condition }\end{array}$ & $\begin{array}{c}\text { Inlet } \\
\text { Mach } \\
\text { number }\end{array}$ & $\begin{array}{c}\text { Inlet } \\
\text { pressure, } \\
\text { MPa }\end{array}$ & $\begin{array}{c}\text { Inlet } \\
\text { temperature, } \\
\mathrm{K}\end{array}$ & $\begin{array}{c}\text { Fue } \\
\text { air } \\
\text { ratio }\end{array}$ \\
\hline Idle & 0.32 & 0.32 & 477 & 0.001 to 0.020 \\
Parametric & .32 & .52 & 589 & $\mathrm{a} .008$ to 0.020 \\
Parametric & .32 & .830 & 589 & $\mathrm{a} .008$ to 0.020 \\
\hline
\end{tabular}

a Maximum fuel-air ratio limited by exit temperature pattern factor. 


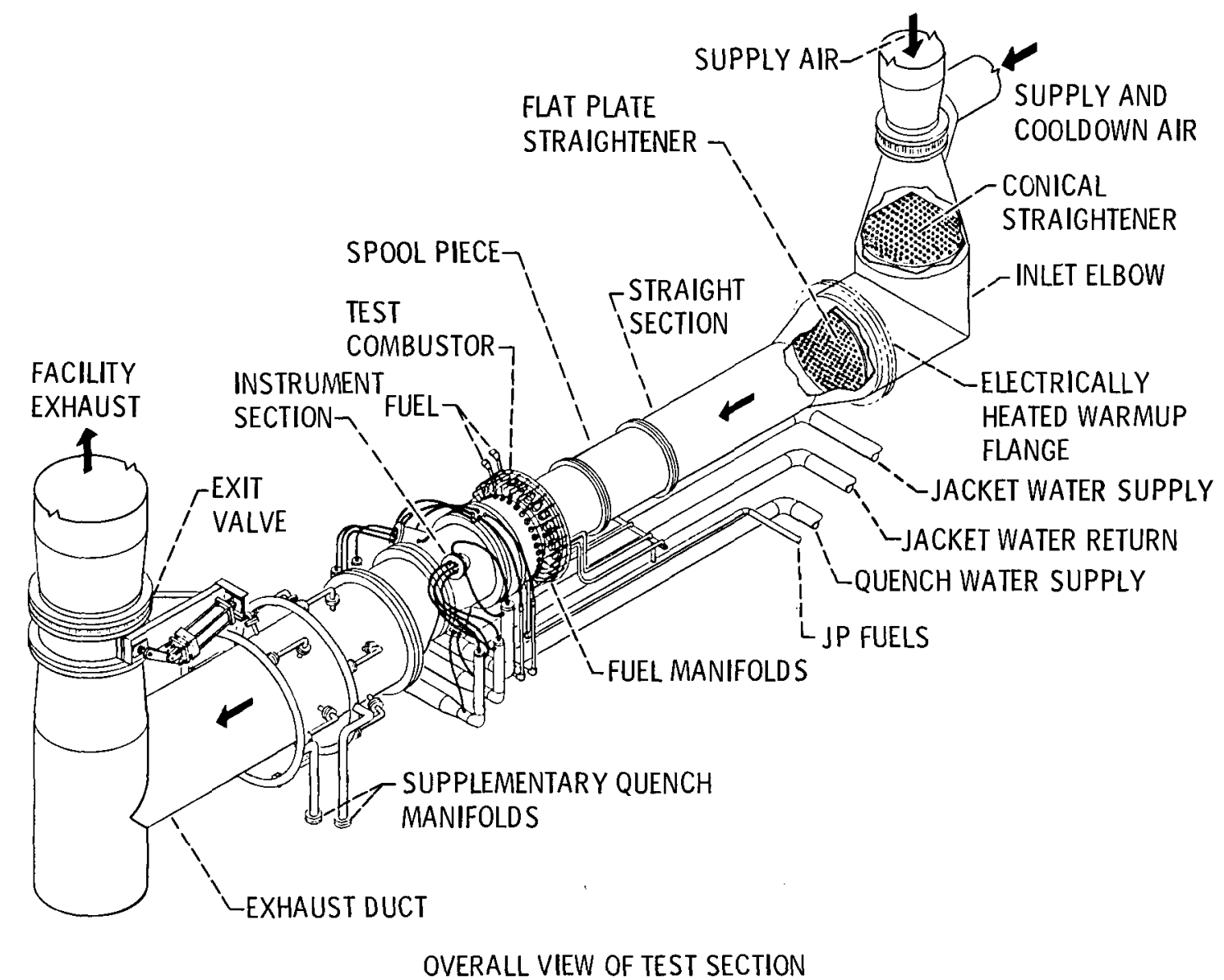

Fig. 1. - Test facility in the engine components research laboratory. 


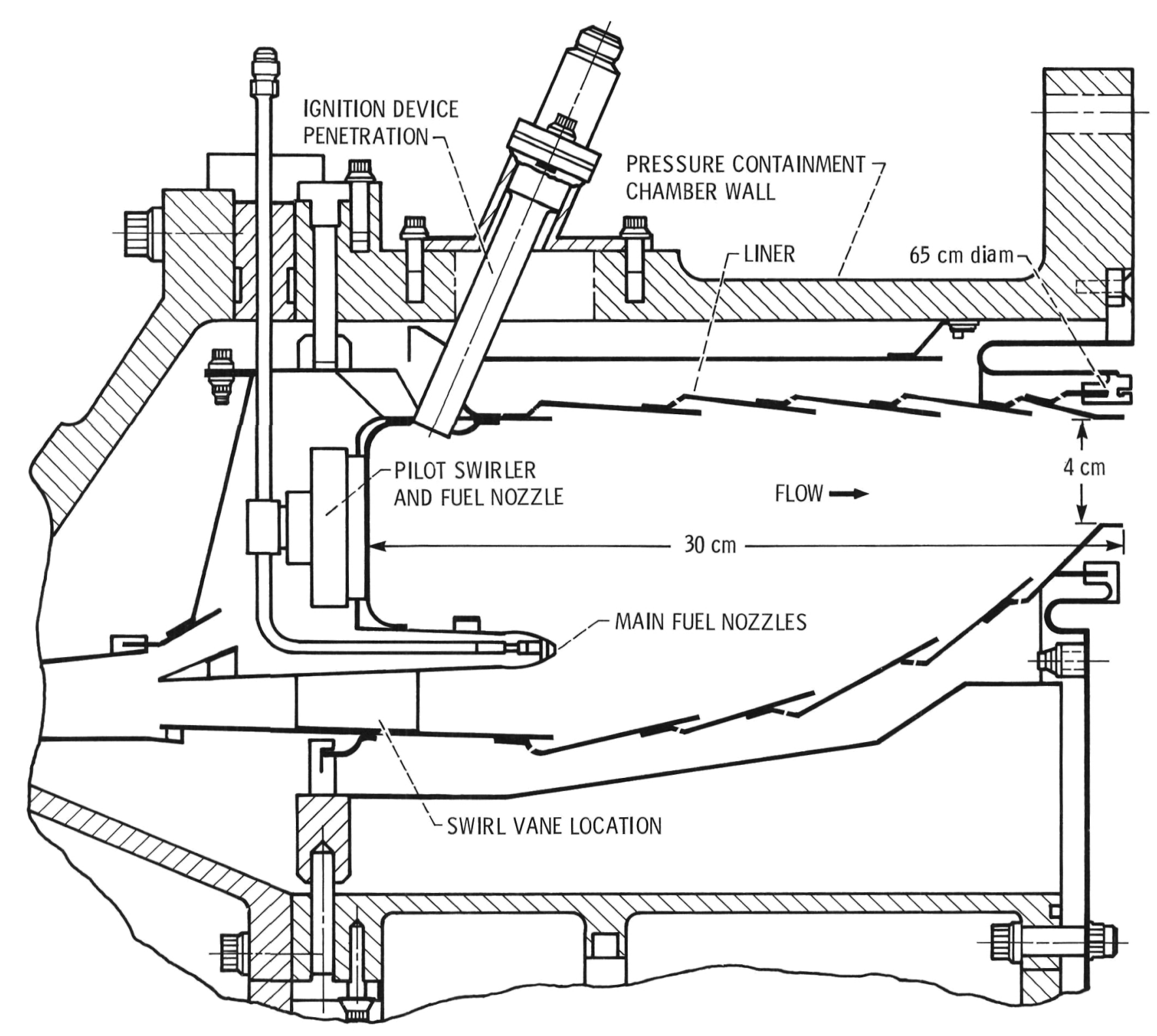

Fig. 2。 - Schematic view of two zone combustor. 

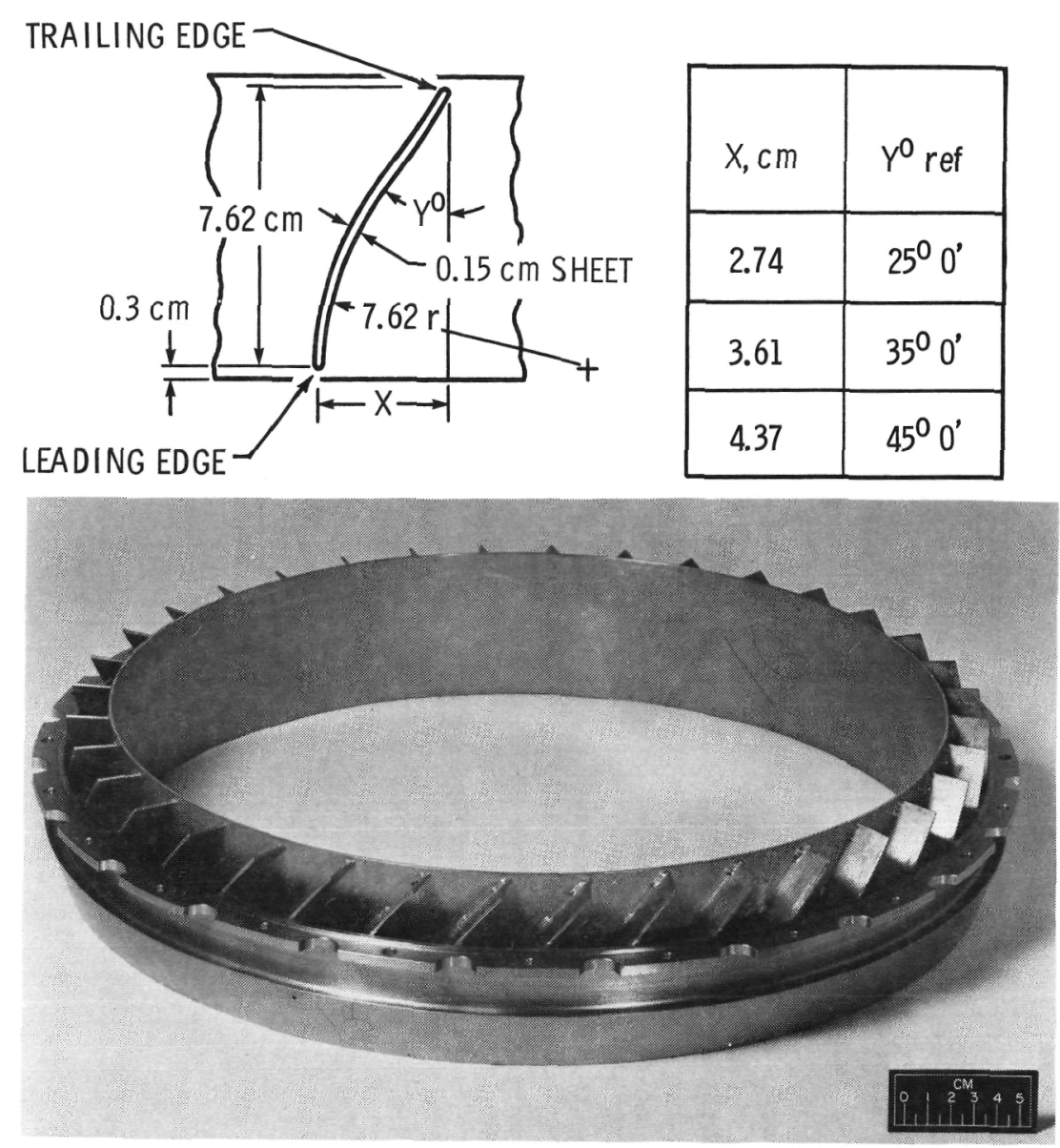

Figure 3. - View of $45^{\circ}$ swirl vanes and swirl vane angle changes.

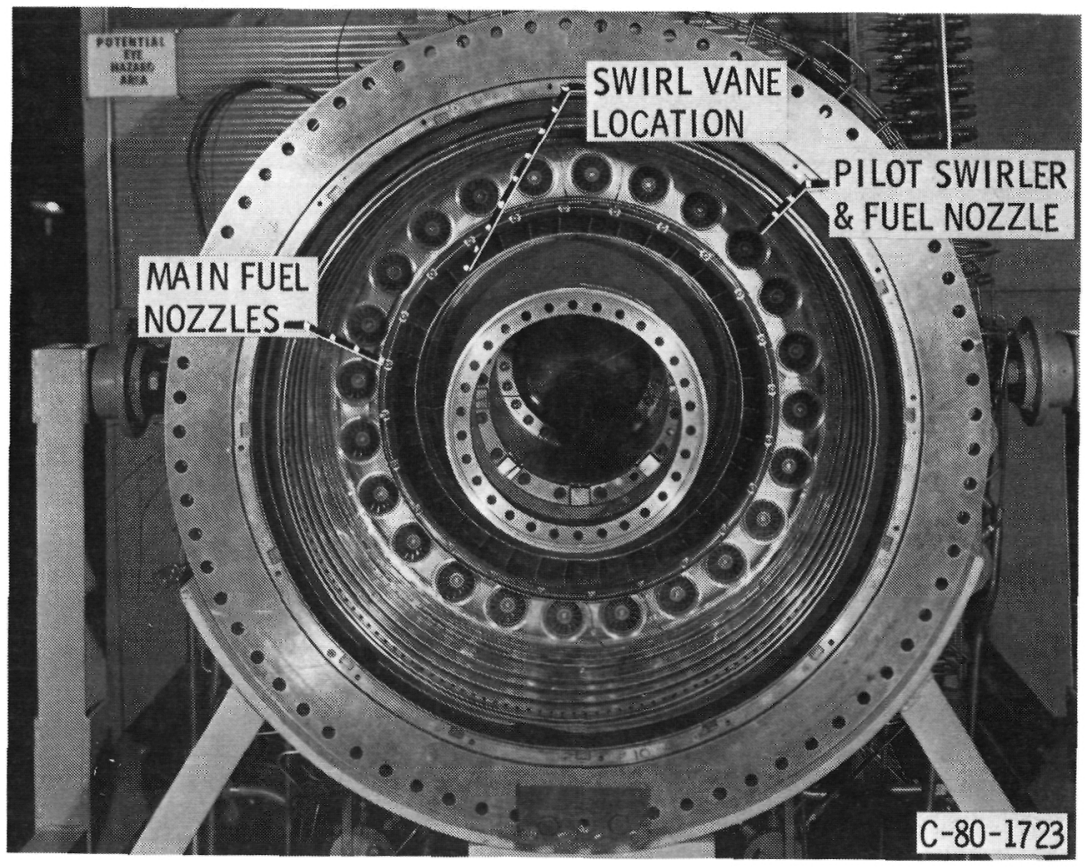

Figure 4. - Swirl flow combustor with inner liner removed. 


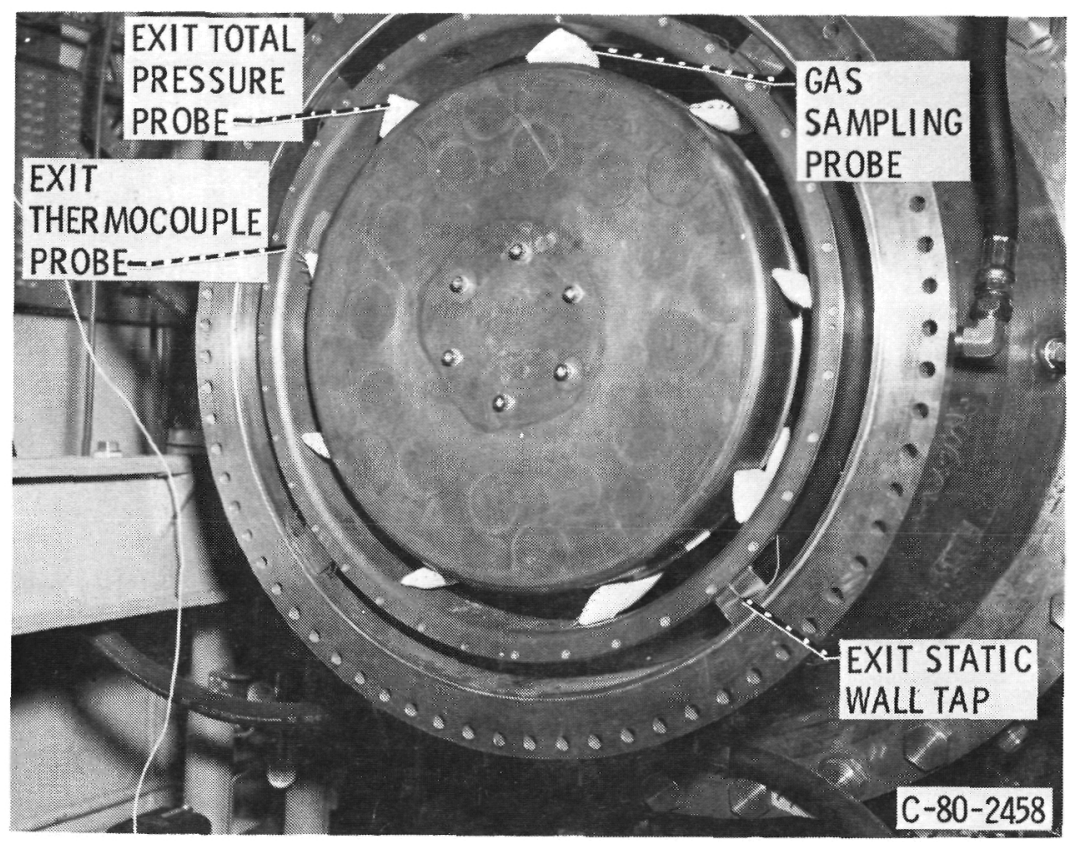

Figure 5. - Exit two zone instrumentation locations.

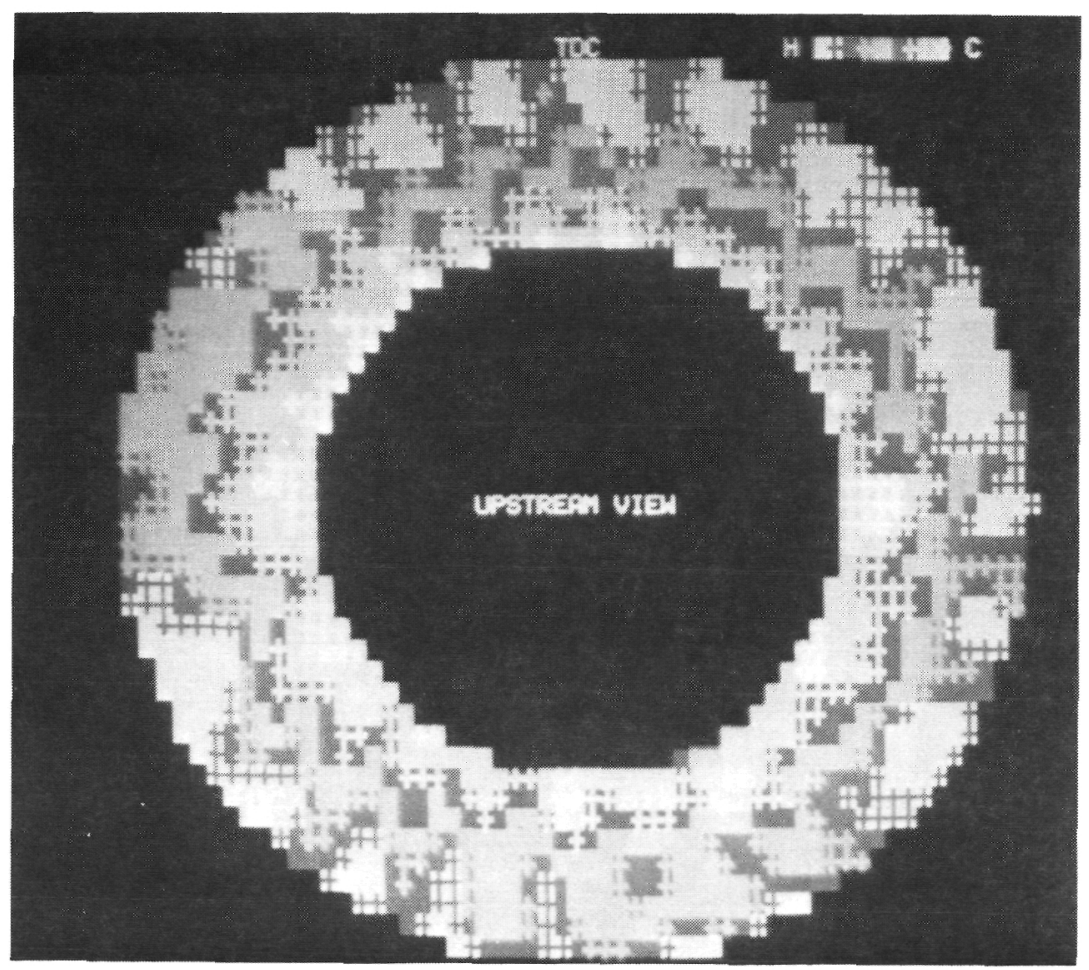

(a) $25^{\circ}$ swirl and pilot only operation.

Figure 6. - Combustor exit profile. 


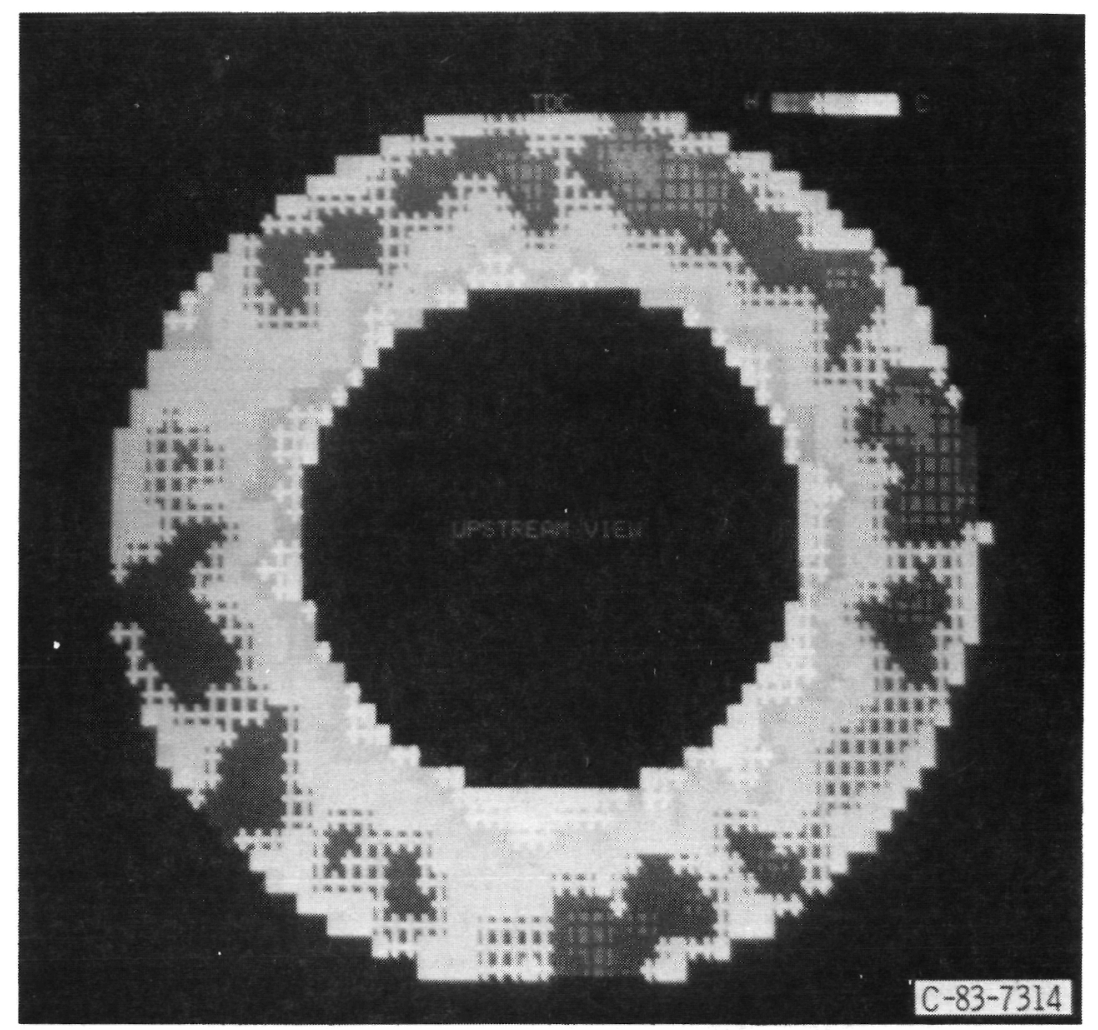

(b) $35^{\circ}$ swirl and pilot only operation.

Figure 6. - Continued.

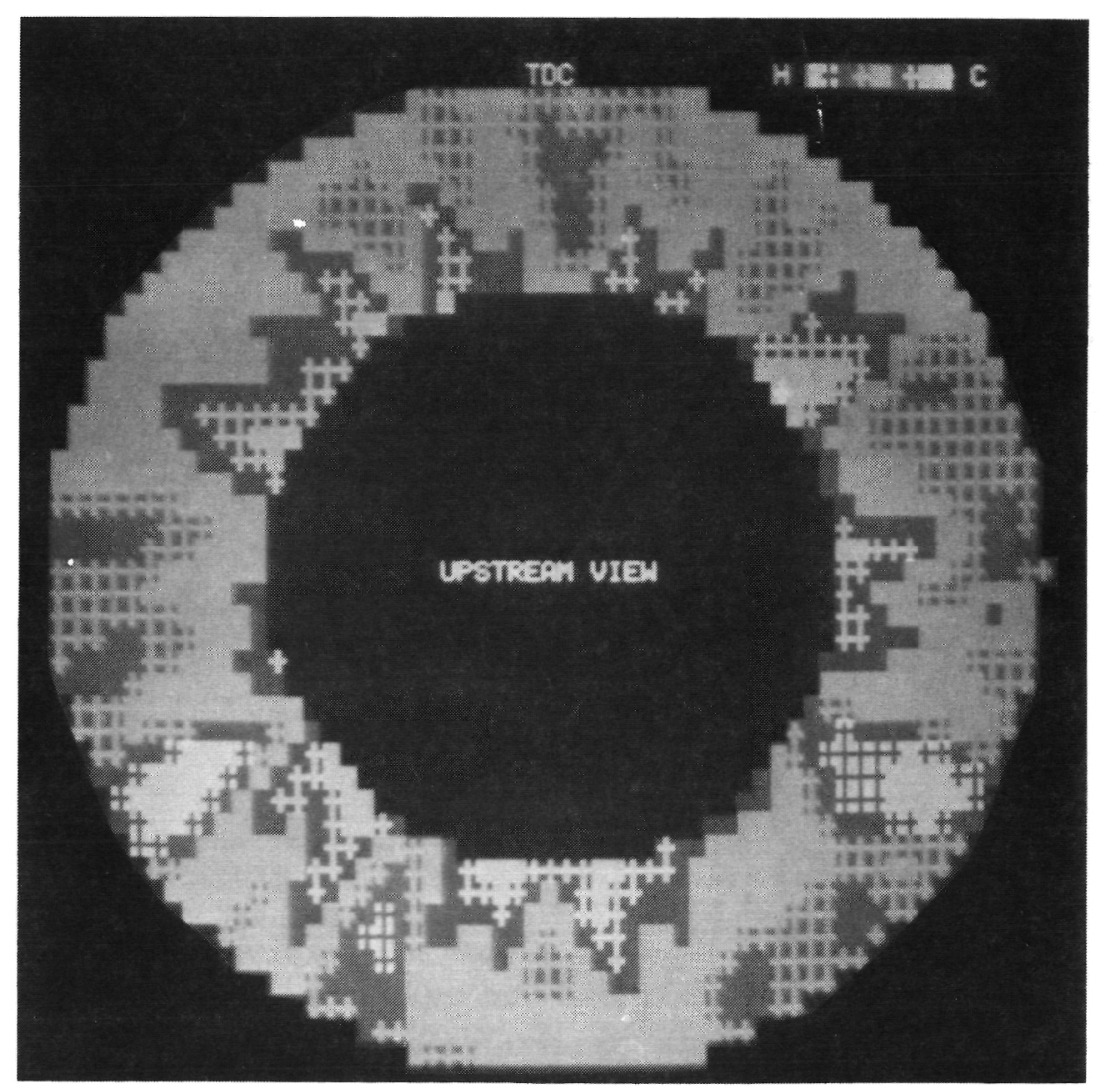

(c) $45^{\circ}$ swirl and pilot only operation.

Figure 6. - Concluded. 


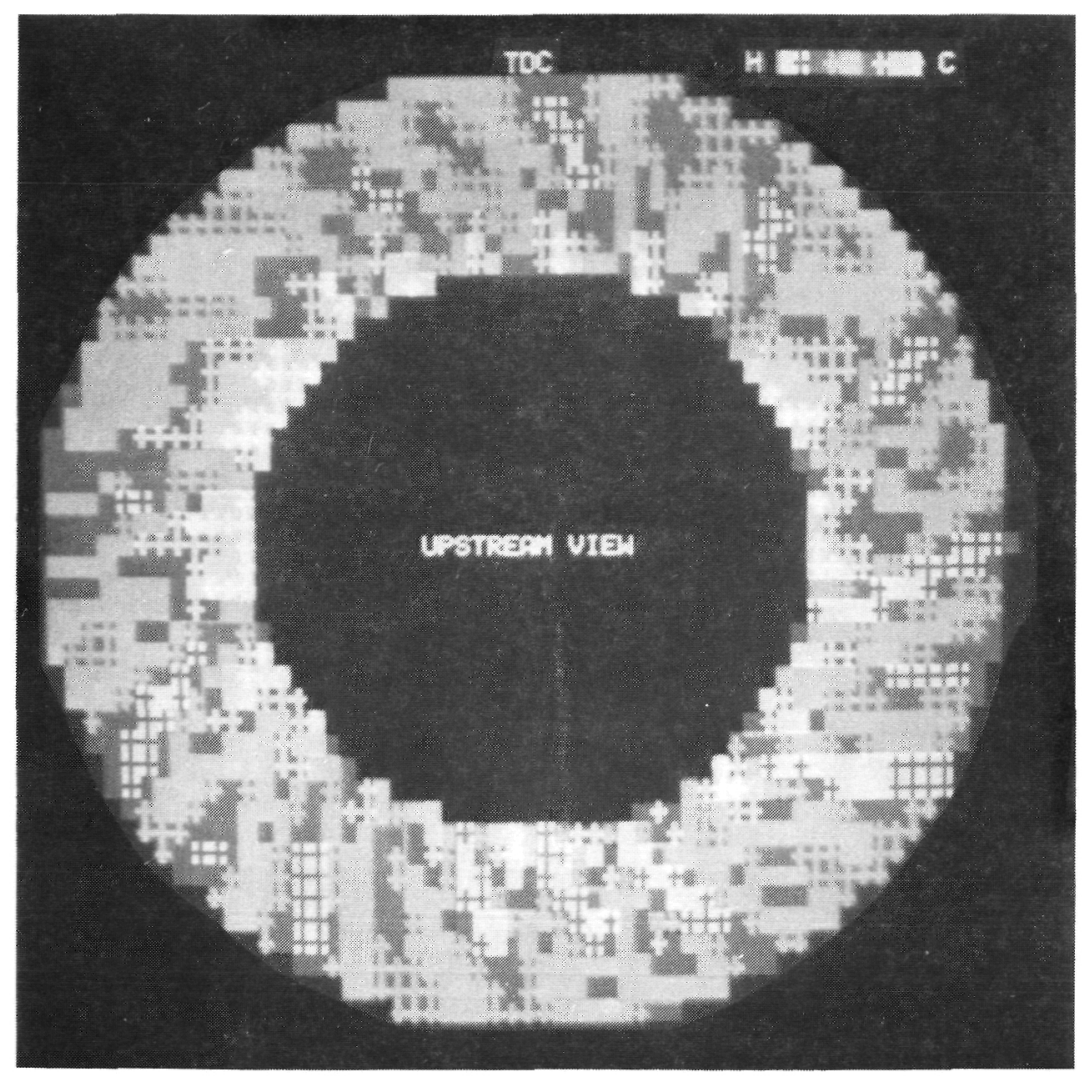

(a) $25^{\circ}$ swirl and pilot and main operation.

Figure 7. - Combustor exit profile. 


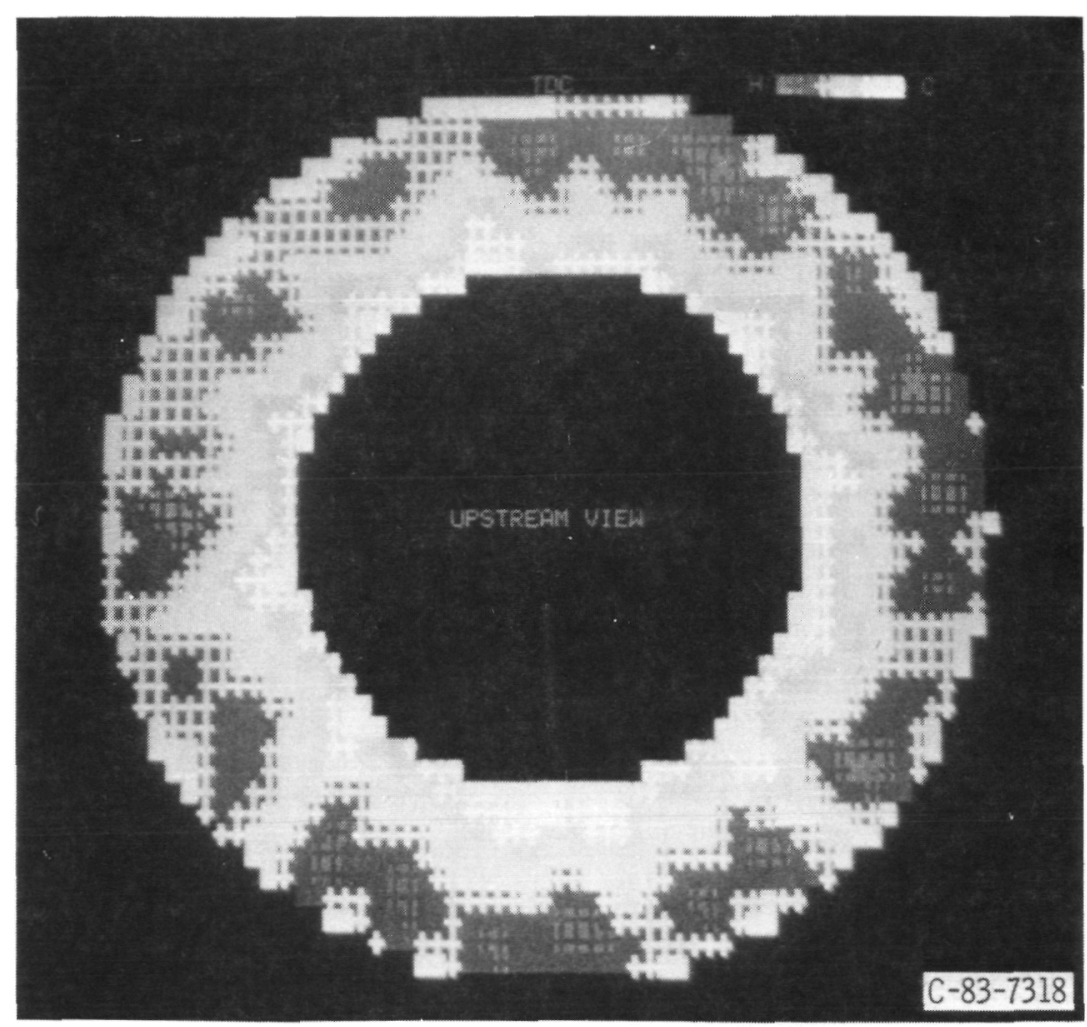

(b) $35^{\circ}$ swirl and pilot and main operation.

Figure 7. - Continued. 


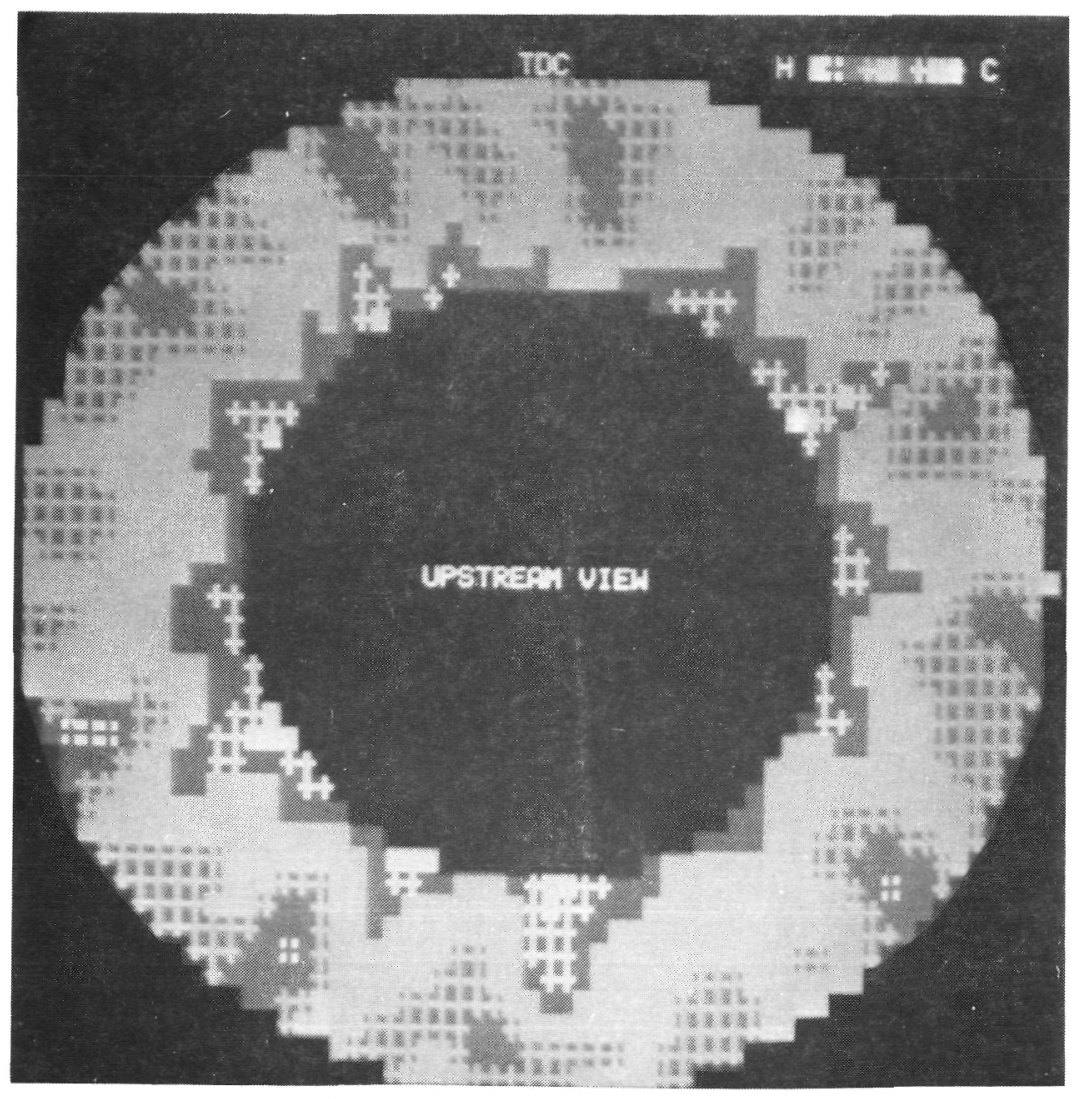

(c) $45^{\circ}$ swirl and pilot and main operation.

Figure 7. - Concluded. 


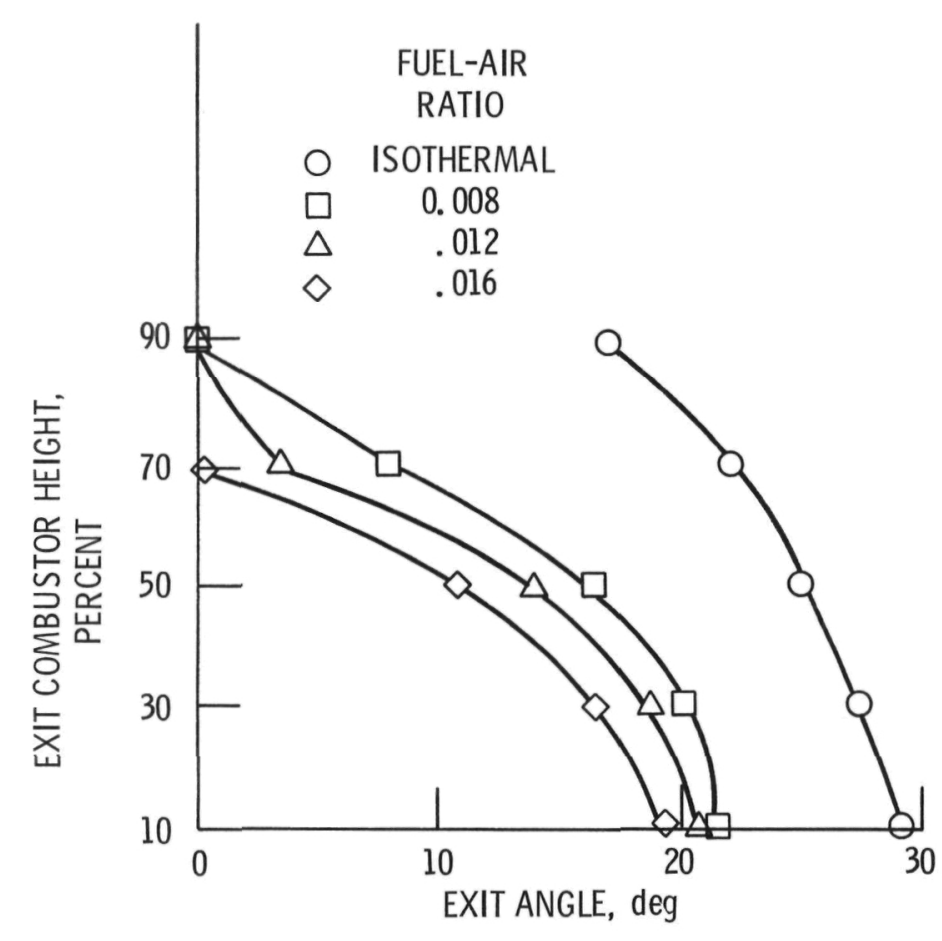

Fig. 8. - Effect of fuel-air ratio on combustor exit swirl angle. Pilot only operation; $35^{\circ}$ swirl vane; parametric test conditions: inlet pressure, $0.83 \mathrm{MPa}$; inlet temperature, $589 \mathrm{~K}$; inlet Mach number, 0.32 .

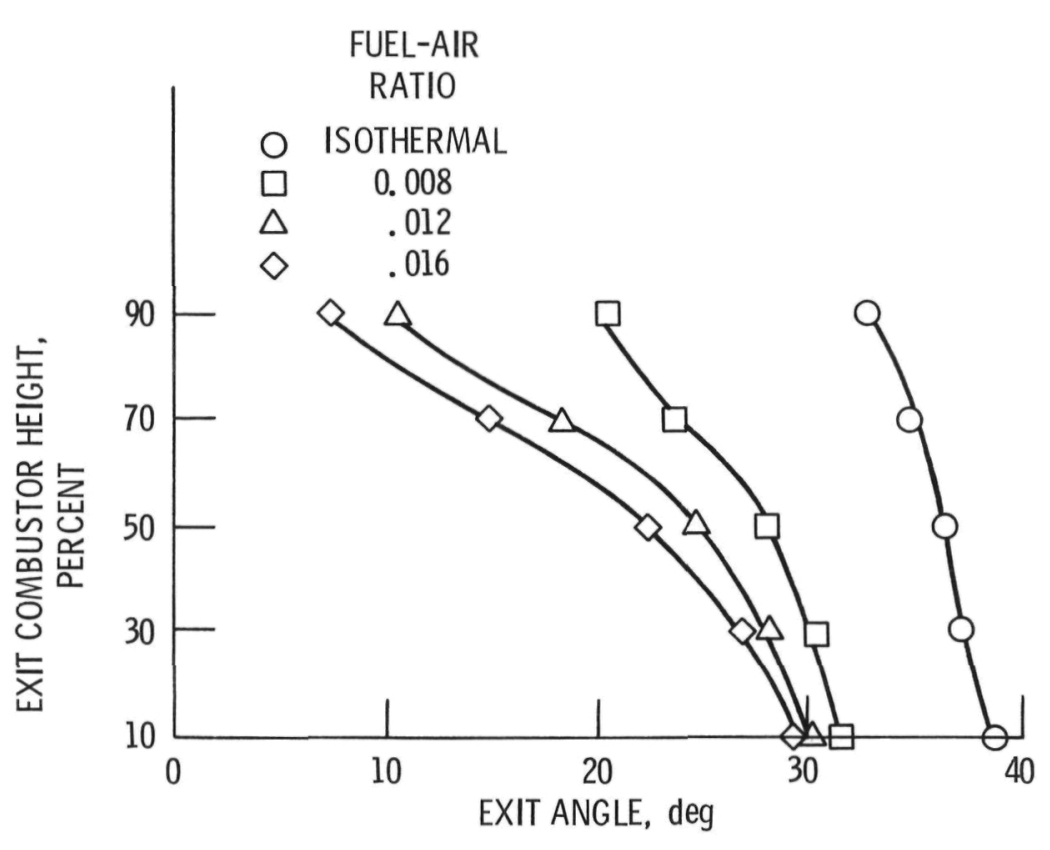

Fig. 9. - Effect of fuel-air ratio on combustor exit angle. Pilot only operation; $4^{\circ}$ swirl vane; parametric test conditions: inlet pressure, $0.517 \mathrm{MPa}$; inlet temperature, $589 \mathrm{~K}$; inlet Mach number, 0.32 


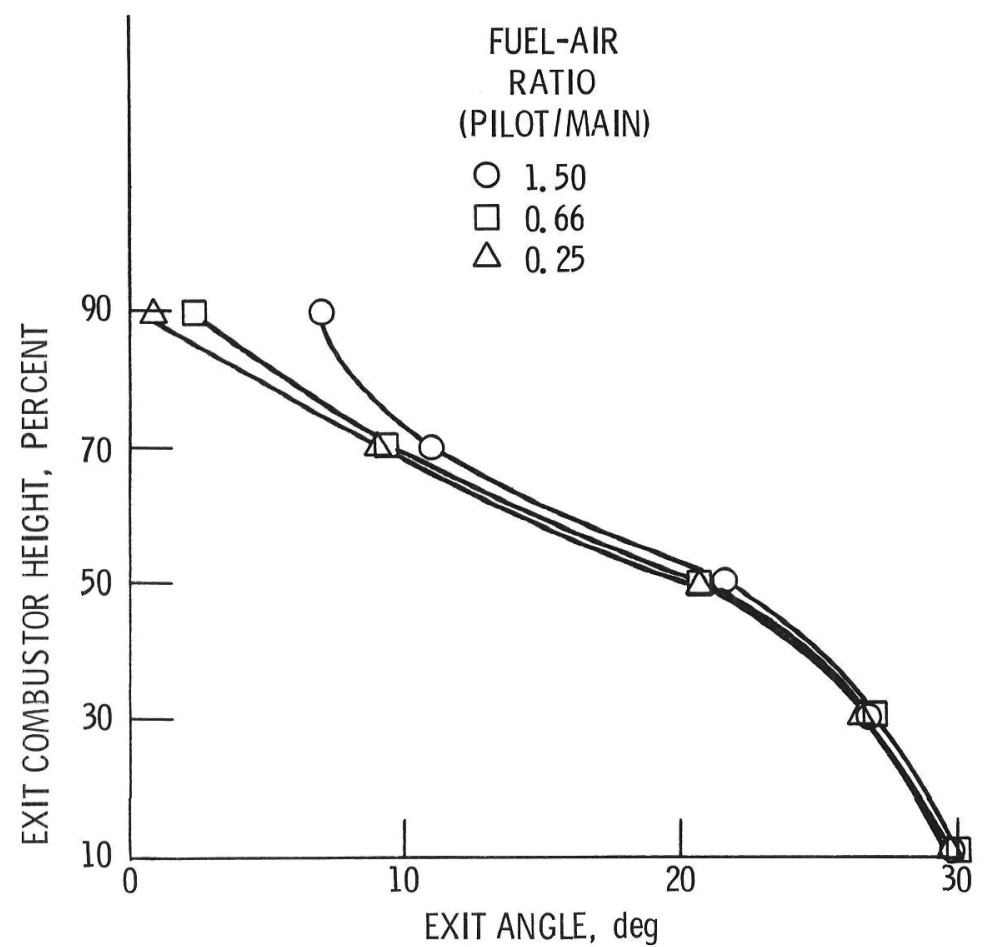

Fig. 10. - Effect of increasing main fuel flow on combustor exit swirl angle. Pilot and main operation; $45^{\circ} \mathrm{swirl}$ vane; parametric test condition; fuel-air ratio, 0.016; inlet pressure, $0.827 \mathrm{MPa}$; inlet temperature, $589 \mathrm{~K}$; inlet Mach number, 0.32.

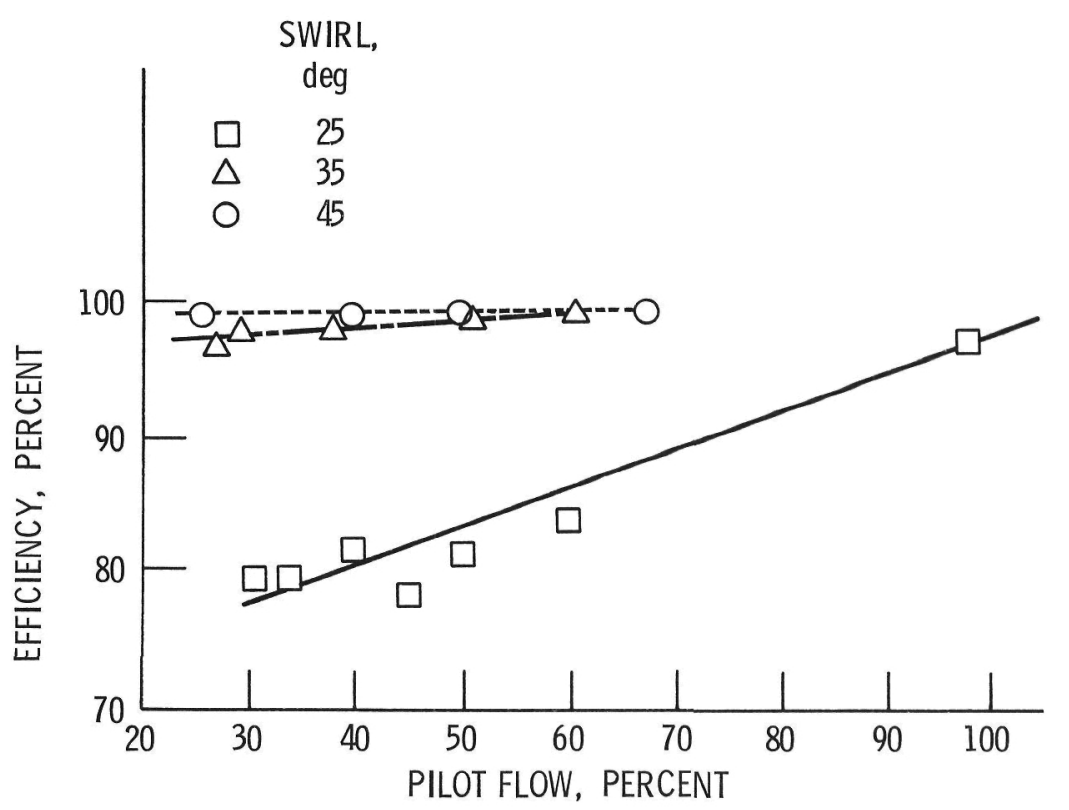

Fig. 11. - Effect of combustor pilot flow on combustor efficiency. Inlet pressure, $0.83 \mathrm{MPa}$; inlet temperature, $589 \mathrm{~K}$; inlet Mach number, 0.32 


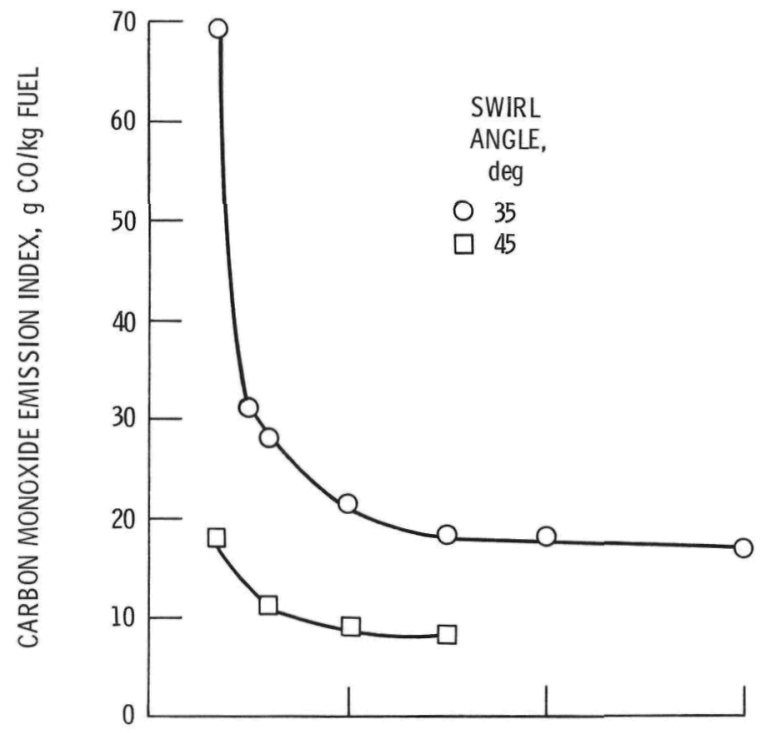

(a) Carbon monoxide.

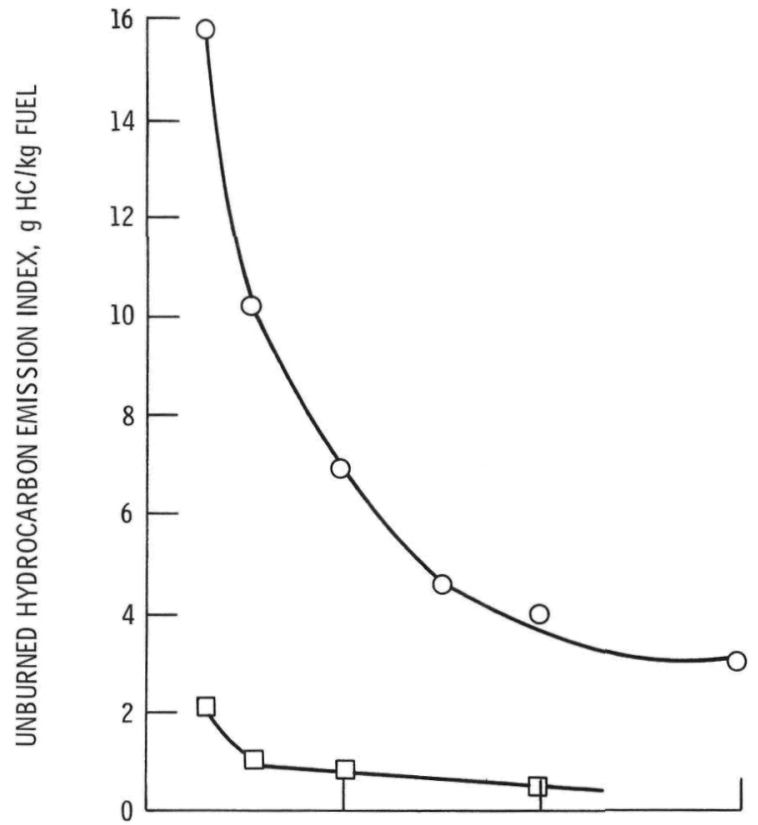

(b) Unburned hydrocarbon.

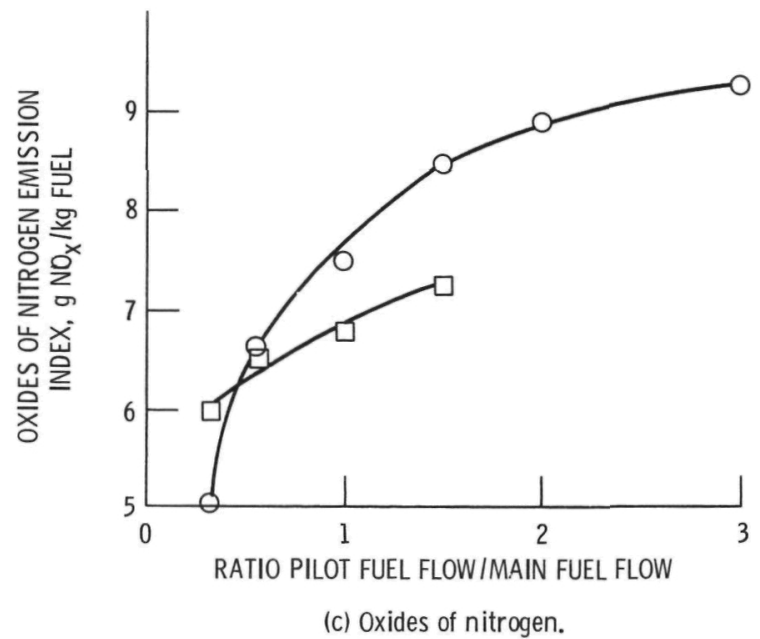

Fig. 12. - Effect of swirl vane angle. Parametric test conditions: $\mathrm{P}_{\mathrm{IN}}, 0.517 \mathrm{MPa} ; \mathrm{T}_{\mathrm{IN}}, 589 \mathrm{~K} ; \mathrm{M}_{3}, 0.32$ 


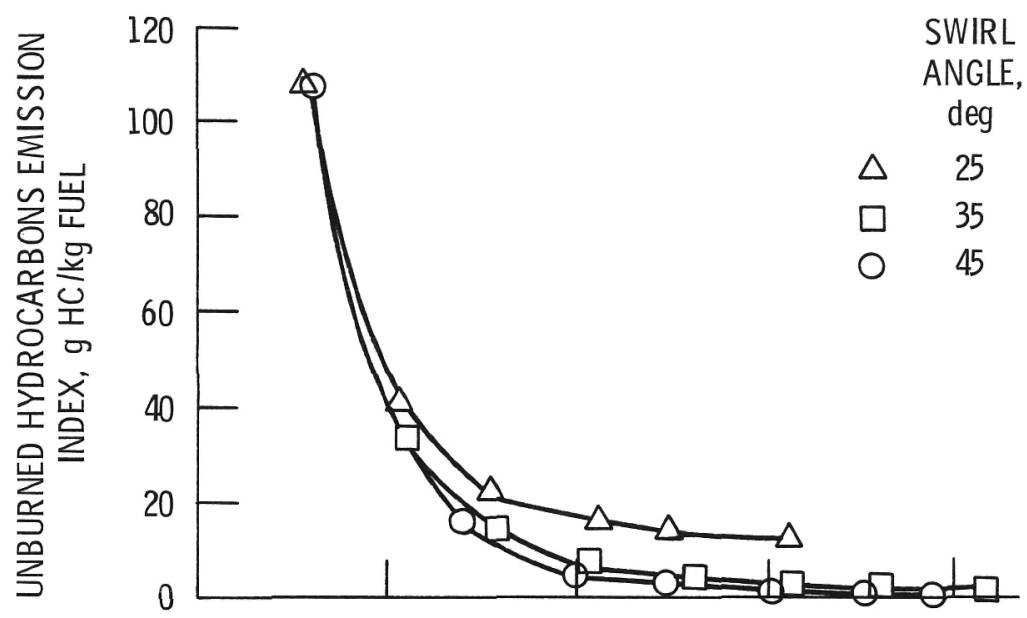

(a) Unburned hydrocarbons.

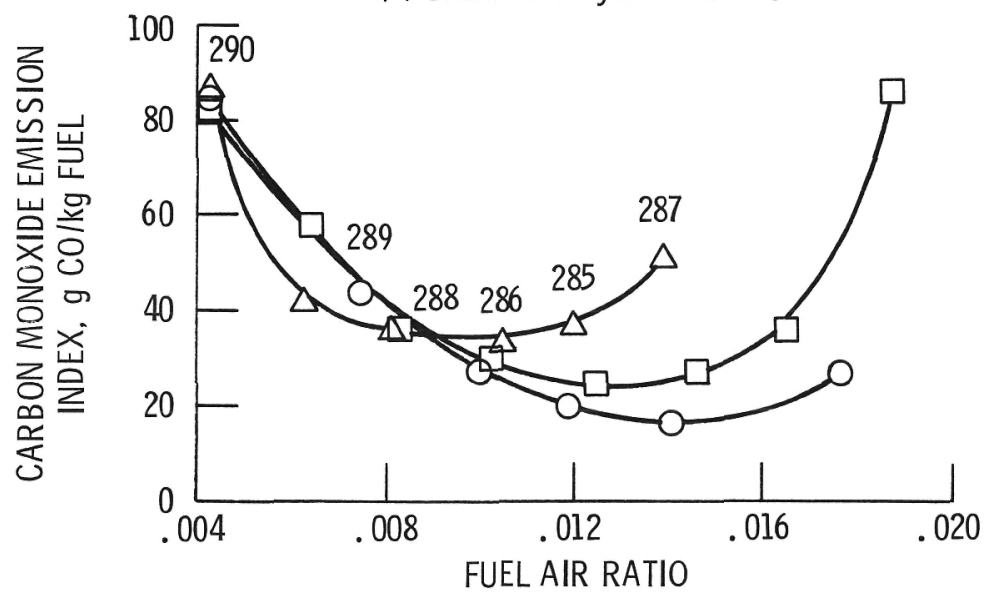

(b) Carbon monoxide.

Fig. 13. - Effect of swirler angle at idle. Idle conditions: $\mathrm{P}_{\mathrm{IN}}, 0.32 \mathrm{MPa} ; \mathrm{T}_{\mathrm{IN}}, 477 \mathrm{~K} ; \mathrm{M}_{3}, 0.32$. 


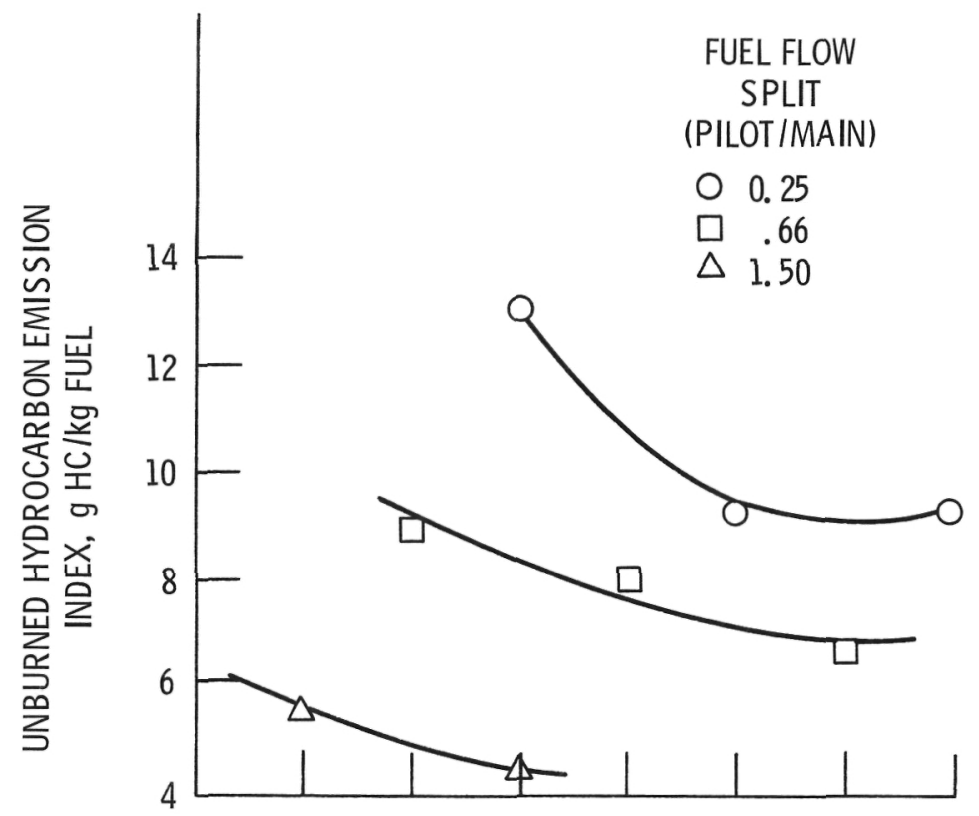

(a) Unburned hydrocarbons.

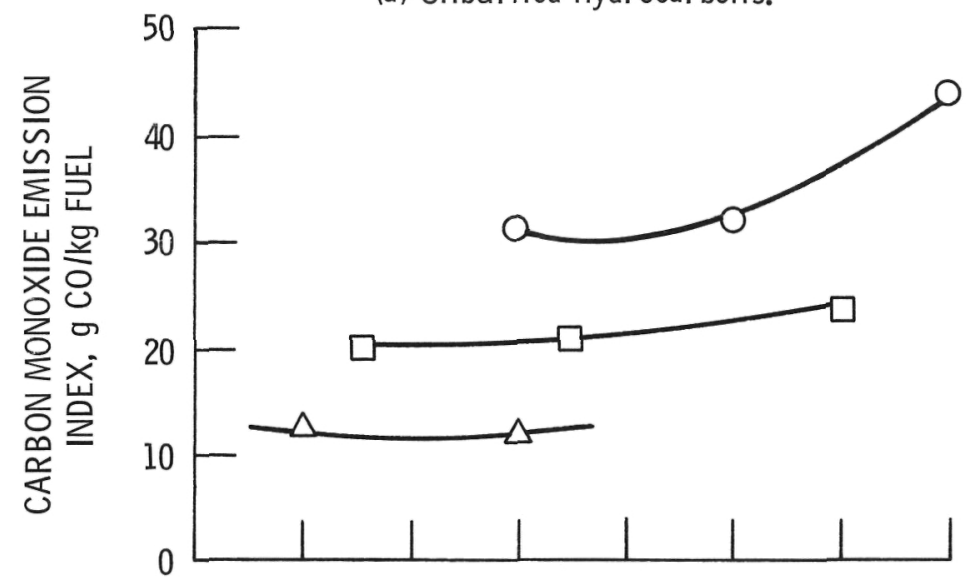

(b) Carbon monoxide.

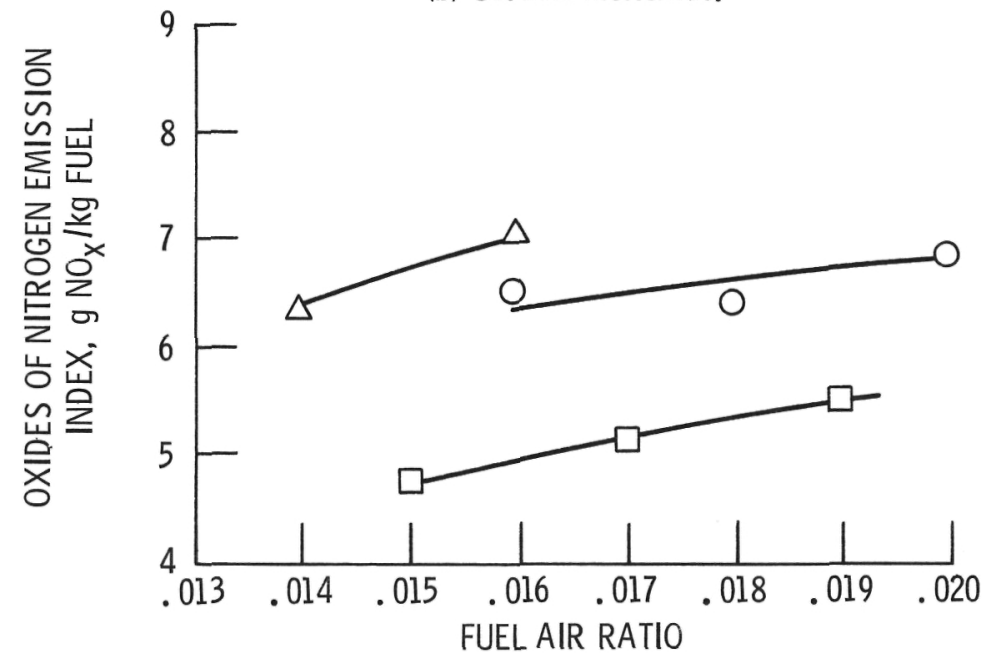

(c) Oxides of nitrogen.

Fig. 14. - Effect of fuel flow split Parametric test conditions: $P_{I_{N}}, 0.83 \mathrm{MPa} ; T_{I N}, 589 \mathrm{~K} ; M_{3}, 0.32$. 


\begin{tabular}{|c|c|c|c|}
\hline $\begin{array}{l}\text { 1. Report No. } \\
\text { NASA TM- } 83637\end{array}$ & 2. Government Accession No. & \multicolumn{2}{|c|}{ 3. Recipient's Catalog No. } \\
\hline \multicolumn{2}{|c|}{$\begin{array}{l}\text { Preliminary Investigation of a Two-Zone Swirl Flow } \\
\text { Combustor }\end{array}$} & \multicolumn{2}{|l|}{ 5. Report Date } \\
\hline \multirow{2}{*}{\multicolumn{2}{|c|}{$\begin{array}{l}\text { 7. Author(s) } \\
\text { James A. Biaglow, Susan M. Johnson, and John M. Smith }\end{array}$}} & \multicolumn{2}{|c|}{$\begin{array}{l}\text { 8. Performing Organization Report No. } \\
\text { E-2029 }\end{array}$} \\
\hline & & \multicolumn{2}{|c|}{ 10. Work Unit No. } \\
\hline \multicolumn{2}{|c|}{$\begin{array}{l}\text { 9. Pertorming Organization Name and Address } \\
\text { National Aeronautics and Space Administration } \\
\text { Lewis Research Center } \\
\text { Cleveland, Ohio } 44135\end{array}$} & \multicolumn{2}{|c|}{ 11. Contract or Grant No. } \\
\hline \multirow{2}{*}{\multicolumn{2}{|c|}{$\begin{array}{l}\text { 12. Sponsoring Agency Name and Address } \\
\text { National Aeronautics and Space Administration } \\
\text { Washington, D.C. } 20546\end{array}$}} & \multicolumn{2}{|c|}{$\begin{array}{l}\text { 13. Type of Report and Period Covered } \\
\text { Technical Memorandum }\end{array}$} \\
\hline & & \multicolumn{2}{|c|}{ 14. Sponsoring Agency Code } \\
\hline \multirow{2}{*}{\multicolumn{4}{|c|}{$\begin{array}{l}\text { 15. Supplementary Notes } \\
\text { Prepared for the Twentieth Joint Propulsion Conference cosponsored by the AIAA, } \\
\text { SAE, and ASME, Cincinnati, Ohio, June } 11-13 \text {, } 1984 \text {. }\end{array}$}} \\
\hline & & & \\
\hline \multicolumn{4}{|c|}{$\begin{array}{l}\text { 16. Abstract } \\
\text { An experimental investigation was conducted to determine the effect of full- } \\
\text { annular swirling-flow on a two-zone combustor design. Swirl flow angles of } 25 \text {, } \\
35 \text {, and } 45 \text { degrees were investigated in a combustor design envelope typical of } \\
\text { those used in modern engines. The two-zone combustor had } 24 \text { pilot-zone fuel } \\
\text { injectors and } 24 \text { main-fuel injectors located in the centerbody between the pilot } \\
\text { and swirl passage. Combustor performance was determined at idle, and two param- } \\
\text { etric } 589 \mathrm{~K} \text { inlet temperature conditions. Combustor performance was highest } \\
\text { with the } 45 \text { degree swirl vane design; at the idle condition combustion efficiency } \\
\text { was } 99.5 \text { percent. The } 45 \text { degree swirl vane also produced the lowest pattern } \\
\text { factor of the three angles and showed a combustor lean blowout limit below a } \\
\text { 0.001 fuel-air ratio. Combustor total pressure drop varied from a low of } 4.6 \\
\text { percent for the } 25 \text { degree swirl to a high of } 4.9 \text { percent for the } 45 \text { degree swirl. }\end{array}$} \\
\hline \multicolumn{4}{|l|}{ 17. Key Words (Suggested by Author(s)) } \\
\hline $\begin{array}{l}\text { Swirl flow } \\
\text { Full annular combustor } \\
\text { Combustor }\end{array}$ & $\begin{array}{l}\text { Unclassifie } \\
\text { STAR Categc }\end{array}$ & $\begin{array}{l}- \text { unlimitec } \\
07\end{array}$ & \\
\hline $\begin{array}{l}\text { 19. Securlty Classif. (of this report) } \\
\text { Unclass i fi ed }\end{array}$ & $\begin{array}{l}\text { o. Security Classif. (of this page) } \\
\text { Unclass i fi ed }\end{array}$ & 21. No. of pages & 22. Price ${ }^{\circ}$ \\
\hline
\end{tabular}

"For sale by the National Technical Information Service, Springfield, Virginia 22161 
National Aeronautics and Space Administration

Washington, D.C.

20546

Official Business

Penalty for Private Use, $\$ 300$
SPECIAL FOURTH CLASS MAIL BOOK

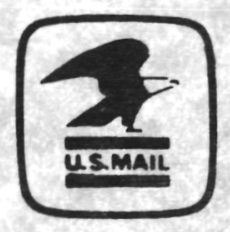

Postage and Fees Paid National Aeronautics and Space Administration NASA-451

POSTMASTER: 